\title{
CRÓNICA DE UNA PEQUEÑA HISTORIA DE MARACAIBO. LA VESTIMENTA FEMENINA Y LAS AUTORIDADES DE LA COLONIA ${ }^{1}$
}

\author{
María Dolores FUENTES BAJO \\ Universidad de Cádiz
}

\begin{abstract}
RESUMEN: En las siguientes páginas exponemos nuestras reflexiones a raíz de determinados acontecimientos ocurridos en Maracaibo, Venezuela, a finales de la colonia. Unos sucesos en apariencia puntuales -el excesivo celo de los eclesiásticos de una parroquia y las tensiones que ello originó con los representantes del monarca- que nos van a servir de punto de partida para reconstruir la mentalidad y los valores de una época, indudablemente, de transición.

PALABRAS CLAVE: Siglo XVIII, Venezuela, Provincia de Mérida-Maracaibo, Juan Ramos de Lora, Juan Antonio Troconis, Rafael Delgado, Mujer, Vestido Femenino.

ABSTRACT: On the following pages we express our thoughts of specific events that occurred in Maracaibo,Venezuela, at the end of the colonial time. Some apparently concrete events - the excessive zeal of the clergy of a parish and the tensions with the king's ministers that originated from this - that are going to serve the point of rebuilding the mentality and values of an era, undoubtedly an era of transition.

KEYWORDS: 18th century, Venezuela, the province of Mérida-Maracaibo, Juan Ramos de Lora, Juan Antonio Troconis, Rafael Delgado, Woman, Female Dress.
\end{abstract}

Algunas puntualizaciones sobre este trabajo, como aclaración preliminar. Se ha documentado nuestra investigación en expedientes procedentes de diferentes repositorios. En el Archivo General de Indias, de Sevilla, tuvimos la oportunidad de descubrir la parte central del trabajo: los edictos del obispo de la diócesis de Mérida-Maracaibo sobre las pautas a que debía ajustarse la vestimenta femenina en el interior de los templos. Otros personajes involucrados en los hechos que se estudian resultaron igualmente atractivos; en concreto, nos referimos a un militar de Maracaibo que reaccionó airadamente contra las citadas normativas de Ramos de Lora y, sobre todo, contra la forma de llevarlas a efecto determinados sacerdotes

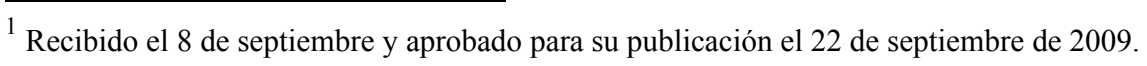


de la ciudad. Viajamos, así, a la localidad de Navalcarnero en la provincia de Madrid, lugar de nacimiento del susodicho militar, donde tuvimos ocasión de documentarnos sobre los años anteriores a su partida a América. Pero no concluyeron aquí nuestras pesquisas pues, para seguir los pasos de su dilatada carrera militar, nos fue preciso acudir al Archivo General de Simancas, en Valladolid.

Estudiemos, de forma ordenada, el tema que proponemos; en primer lugar, conviene dar unas pinceladas sobre Maracaibo, donde se desarrolla nuestra historia.

\section{MARACAIBO, ESCENARIO DE NUESTRA PEQUEÑA HISTORIA.}

Maracaibo era, desde el punto de vista administrativo, la primera y principal ciudad de una provincia situada en la parte más occidental de la actual República de Venezuela. Puede decirse que inicia su andadura colonial mediado el siglo XVI. En síntesis, podrían distinguirse dos periodos; correspondería el primero a su formación. Es entonces cuando el territorio se ve recorrido por muchas y diferentes huestes, unas vinculadas a Santa Fe de Bogotá, mientras otras dependían de forma directa de las autoridades de Caracas y Coro. De forma escalonada y no demasiado fácil fueron definiéndose los diferentes núcleos poblacionales de nuestra región. La ciudad que interesa para nuestro trabajo, Nueva Zamora de la Laguna de Maracaibo, no es una excepción y asimismo tuvo unos comienzos inciertos, con diferentes fundaciones $(1529,1569,1574)$ y abandonos.

La gobernación aparece reseñada con diversos nombres a lo largo de su historia y, por lo que mira a su organización política, tuvo también distintas capitales; el territorio bajo su jurisdicción se vio modificado, igualmente, a lo largo de esta fase. La fecha de 1573 puede servir de punto de partida: tuvo lugar entonces el nacimiento de la "Gobernación de La Grita". Su existencia fue, sin embargo, bastante precaria, razón por la que se le agregaron otros territorios desgajados del Corregimiento de Tunja, como Mérida y San Cristóbal. Este es el origen del nuevo "Corregimiento de Mérida del Espíritu Santo" (1607), convertido algún tiempo después, en 1622, en la "Provincia, Gobernación y Capitania General de Mérida". Al finalizar el siglo, en 1676, se incorporó Maracaibo que poco tiempo después (en 1678), gracias al traslado allí de las autoridades de la zona, quedará convertida en capital de la "Provincia de Mérida, La Grita y Ciudad de Maracaibo"

La trayectoria un tanto errática de Maracaibo en este periodo no fue un fenómeno aislado; otras gobernaciones desperdigadas por Tierra Firme sufrieron por aquel entonces dificultades similares, al aglutinar regiones con importantes 
diferencias y contrastes entre sí. Fue el caso de las provincias de Venezuela, Margarita, Trinidad, Cumaná y Guayana ${ }^{2}$.

Si avanzamos en el tiempo se perciben, al alborear el siglo XVIII, ciertos cambios significativos; podemos fijar entonces el comienzo de una nueva etapa en su historia colonial, la segunda. Determinadas transformaciones serán sintomáticas de los nuevos tiempos. La provincia parece salir ahora de su aislamiento; el primer paso en este sentido, vendrá dado por su anexión al recién creado virreinato de Nueva Granada ${ }^{3}$. No se trató en manera alguna de un proceso fácil, por diferentes circunstancias; en primer lugar, debido a que la propia institución virreinal tardó en consolidarse, como queda patente en el hecho de que debiera ser fundado en dos ocasiones el virreinato: la primera en 1717 y la segunda, ya con carácter definitivo, veinte años más tarde, en 1739. Pero en las no siempre fáciles relaciones entre Maracaibo y Santa Fe de Bogotá pesaron también consideraciones de otro tipo, la más importante de ellas guardaba relación con la provincia en sí misma: las diferencias patentes entre los distintos núcleos poblacionales que la integraban alimentaban una casi endémica rivalidad entre unos y otros que dificultaba a la postre enormemente su gobernabilidad ${ }^{4}$ No obstante, la documentación reseña algún tiempo después, en torno a 1765-1770, una relativa estabilidad política, reflejo probablemente del despegue económico de la región. ${ }^{5}$

Finalizando el siglo XVIII, demasiado tarde probablemente, se da un paso más y nuevas pautas políticas se marcan desde la península Ibérica: Maracaibo y las otras provincias autónomas de Tierra Firme citadas con anterioridad se integran en la Capitanía General de Venezuela (1777). Paralelamente, casi por las mismas fechas, irán apareciendo diferentes instituciones como la Intendencia (1776)_, la Audiencia (1786), el Consulado (1793) y, algo más tarde, el Arzobispado (1804) con sede, todas ellas, en Santiago de León de Caracas- dirigidas a consolidar el nuevo espacio político y, por supuesto, a afianzar el papel de Caracas como

${ }^{2}$ Enrique NóBREGA (1995): «Notas sobre la élite militar en la provincia de Maracaibo: 17501814» en: Mena García, Carmen; Eugenio Martínez, Ángeles y SARABia Viejo, Justina: Venezuela en el Siglo de las Luces. Sevilla-Bogotá: Muñoz Moya y Montraveta editores, pp. 261-267.

${ }^{3}$ Consuelo Maqueda ABReu (2004): «Diplomacia, reformismo y virreinato de Nueva Granada en los inicios del siglo XVIII». Anuario de Historia de Derecho Español, nº 74, pp. 229-290.

4 María Dolores Fuentes BAJO (2005): «Estudio de una provincia: Maracaibo, siglo XVIII». Revista Trocadero, Cádiz n 17, pp. 249-265.

5 Belín VÁsquez De Ferrer (1985): «Maracaibo y su espacio histórico (Siglo XVIII)». Tierra Firme, Caracas n ${ }^{\circ}$ 10, pp. 215-236; María Dolores FuENTES BAJO (2008): «Gobernar en una provincia de frontera: Maracaibo 1750-1775». Revista Historia, Métodos y Enfoques. San Juan (Argentina) nº 1, pp. 9-28. 
capital. ${ }^{6}$ Con respecto a la incidencia de esta política reformista en la región, debemos hacer algunas precisiones pues nuestras fuentes se hacen eco de las reticencias de Maracaibo al nuevo marco político, indicativas de que el proceso topaba con serios obstáculos ${ }^{7}$. En el momento presente es difícil precisar el alcance de estas peticiones: la Corona las obvió manteniendo a la provincia supeditada a las autoridades caraqueñas, debido a su interés por controlar de manera más efectiva la zona, si bien no deja de ser cierto que estas reivindicaciones de la ciudad del lago no habían sido sino silenciadas de forma temporal. Recordemos en este sentido que pocos años más tarde, ante las primeras oleadas independentistas lideradas por Caracas, Maracaibo revivirá sus antiguas pretensiones optando por mantener su fidelidad a la monarquía, al igual que Coro y Guayana, si bien sería detenernos en cuestiones que exceden la temática de este trabajo ${ }^{8}$.

Por otra parte, en este contexto de mayor presencia institucional, debe comprenderse el nuevo obispado de Mérida-Maracaibo. Hasta ese momento, la organización eclesiástica de la provincia era compleja y poco eficaz; así, mientras Maracaibo pertenecía al obispado de Santiago de León de Caracas, el resto de la gobernación estaba vinculado al arzobispado de Bogotá. A esto se unían los perjuicios derivados de las enormes distancias y del mal estado de los caminos, en determinados meses del año. Las peticiones al monarca sobre la conveniencia de una diócesis propia se fechan en diferentes momentos del siglo XVIII, aunque deberán esperar bastante tiempo para convertirse en realidad. En este sentido, se

${ }^{6}$ Manuel NunES DiAs (1972): «Venezuela en las reformas estructurales del sistema colonial español». Memoria del I Congreso Venezolano de Historia. Tomo II. Caracas: Academia Nacional de la Historia, pp. 117-162; Guillermo MoRón (1986): «La Real Audiencia de Caracas: unidad política de Venezuela«. Boletín de la Academia Nacional de la Historia, Caracas no 275, pp. 579-590; Alfonso García-Gallo (1979): «La Capitanía General como institución de gobierno político en España e Indias en el siglo XVIII». Memoria del III Congreso Venezolano de Historia. Tomo I. Caracas: Academia Nacional de la Historia, pp. 535-582; Rafael FERNÁNDEZ Heres (2004): «Factores históricos determinantes para la creación del arzobispado de Caracas (Homenaje con motivo de su bicentenario, 1803-2003)». Boletín de la Academia Nacional de la Historia, Caracas no 346, pp. 169210.

${ }^{7}$ Real cédula de San Ildefonso 13 de agosto de 1784 (Archivo General de Indias, AGI, Caracas 23); real orden a Antonio Ventura de Taranco, de San Lorenzo 6 de octubre de 1784 (AGI, Caracas $31)$.

8 Puede consultarse al respecto el trabajo de Zulimar Maldonado Viloria (2001): «José Domingo Rus: un diputado maracaibero en las Cortes de Cádiz durante la independencia venezolana», en: Poder y mentalidades en España e Iberoamérica (siglos XVI-XX): implicaciones y actores: II Seminario Hispano Venezolano, Maracaibo, pp. 187-207. 
fecha en 1778 la bula de creación del obispado $^{9}$, si bien de hecho no inicia su andadura hasta 1784, año en que fray Juan Ramos de Lora, el primer prelado, desembarca en Maracaibo, después de una larga travesía desde tierras mexicanas ${ }^{10}$.

Los límites del nuevo obispado tardaron en definirse, debido a las reticencias tanto de Santa Fe como de Caracas a ceder curatos y parroquias que tradicionalmente se habían caracterizado por un volumen de diezmos considerable $^{11}$. Otra cuestión que fue objeto de desencuentros fue la relativa al lugar donde se levantaría la nueva catedral; la Bula de Erección designaba con claridad a la ciudad de Mérida sede del nuevo obispado, no obstante el prelado fue objeto de fuertes presiones a su llegada que dilataron un año su permanencia en Maracaibo, en un intento de que se estableciera allí de forma definitiva ${ }^{12}$.Aunque los gobernantes de Madrid hicieron caso omiso de estas cábalas, no se trató de una cuestión baladí; es evidente que bajo esta disputa pueden adivinarse las tensiones que secularmente habían acompañado a la provincia y que aprovechaban cualquier resquicio, por mínimo que fuera, para resurgir.

Después de estas pinceladas sobre la compleja e interesante realidad de Maracaibo a fines del setecientos, las nuevas perspectivas que parecían ofrecerle las remodelaciones borbónicas y, paralelamente, el indudable peso que seguían teniendo determinados desequilibrios internos, parece llegado el momento de avanzar en nuestra pequeña historia, deteniéndonos en sus protagonistas y en las noticias, extensas unas veces, parcas otras, que sobre ellos hemos podido rastrear.

${ }^{9}$ Consulta de 16 de junio de 1777 (AgI, Caracas 10); carta del duque de Grimaldi a José de Gálvez, de Roma 26 de febrero de 1778 (AgI, Caracas 27); carta de Antonio Ventura de Taranco a Francisco de Valencia, de Madrid 11 de noviembre de 1783 (AGI, Caracas 27).

10 Baltasar E. Porras CARDOzo (1992): El ciclo vital de fray Juan Ramos de Lora. Mérida: Ediciones del Rectorado-Universidad de los Andes; Odilo GómEZ PARENTE (1972): Fray Juan Ramos de Lora, obispo insigne y sembrador de cultura: Documentos inéditos sobre su vida y actividad al frente de la diócesis de Mérida de Maracaibo. En el 250 aniversario de su natalicio Los PalaciosSevilla (1722-1972). Caracas: Edición del Ejecutivo del Estado Mérida; del mismo autor (1974), Ilustrísimo padre fray Juan Ramos de Lora, fundador de la Universidad de los Andes. Caracas: Universidad Católica “Andrés Bello" Instituto de Investigaciones Históricas.

${ }^{11}$ Real orden a Antonio Ventura de Taranco, de San Ildefonso 28 de septiembre de 1784; otra real orden al mismo destinatario de San Lorenzo 1 de octubre de 1784; resumen del Consejo de Indias de una carta del obispo Juan Ramos de Lora, de Maracaibo 4 de enero de 1785. Estos documentos en AGI, Caracas 27.

${ }^{12}$ Carta $\mathrm{n}^{\mathrm{o}} 19$ del gobernador de Maracaibo Francisco de Arce a José de Gálvez, de Maracaibo 6 de abril de 1784 (AgI, Caracas 146); real orden a Antonio Ventura de Taranco, de Palacio 28 de diciembre de 1784 (AgI, Caracas 27); real orden a Ventura de Taranco, de Aranjuez 1 de junio de 1785 (AgI, Caracas 31; otra real orden a Ventura de Taranco, de San Ildefonso 5 de septiembre de 1785 (AGI, Caracas 31). 


\section{LOS ACTORES}

En los acontecimientos que tuvieron lugar en la parroquia más antigua de Maracaibo, en los primeros días de $1790^{13}$, se vieron involucradas diferentes personas, unas de forma directa y otras, sin embargo, indirectamente. De una parte se situarían eclesiásticos como Juan Antonio Troconis quien era el cura párroco y vicario eclesiástico. A Troconis correspondería un destacado primer lugar en nuestra lista pues fue el responsable de llevar a efecto las recomendaciones del obispado sobre vestimenta femenina que ocasionaron tanto revuelo en la feligresía. Había nacido en Maracaibo y rondaba los 60 años, cuando tuvieron lugar los hechos en cuestión, según declaran diferentes testigos. Sabemos que pertenecía al clero secular y que desde 1778 era cura de la parroquia de Maracaibo ${ }^{14}$; tenía el título de doctor, aunque no se puede precisar mucho más. En 1799, fue presentado para una ración en la catedral de Mérida ${ }^{15}$.

En segundo lugar, debemos reseñar el nombre de otro eclesiástico, Juan Ramos de Lora, obispo de la joven diócesis de Mérida. Por aquellas fechas se acercaba a los 70 años y su salud estaba seriamente resentida. En la Navidad de 1789 se fechan los edictos suyos que motivaron la polémica, uno de los cuales fue leído a los parroquianos de Maracaibo en ocasión tan señalada como la Misa del Gallo.

${ }^{13}$ La iglesia matriz a que se refiere el documento se ubicaba en la actual Plaza Bolívar. Construida a finales del siglo XVI de bahareque y palma sufrió diferentes remodelaciones. En 1600 fue dedicada a los apóstoles Pedro y Pablo. En 1813 fue consagrada catedral de la diócesis de Mérida de Maracaibo, si bien en 1821 se trasladó de nuevo a Mérida la sede episcopal. Con posterioridad, en 1879, tras la erección de la diócesis del Zulia, recobra su dignidad de catedral. En 1965 es elevada al rango de metropolitana. Véase, Miguel SEMPERE MARTínez (2000): Maracaibo, ciudad y arquitectura. Universidad del Zulia, Facultad de Arquitectura y Diseño: Ediciones Astro Data, pp. 3738

${ }^{14}$ Con anterioridad, fueron párrocos de Maracaibo el bachiller Dn. Juan Baptista de Oberto y el Dr. Dn. Narciso de Yepez. Véanse las declaraciones de los testigos María Josefa Zepeda (de 5 de julio de 1790), María Soledad Carrasquero (de 6 de julio), Melchora Suárez (de 7 de julio), María Josefa Perozo Prieto (de 8 de julio) y José de Soto (de 12 de julio). AgI, Caracas 375.

${ }^{15}$ Real orden a Francisco Moñino, de Palacio 2 de diciembre de 1788 (AgI, Caracas, 27); lista de los prebendados de la iglesia metropolitana de Santa Fe que tienen ascenso a las dignidades de arcediano, chantre, maestrescuela y tesorero de la propia iglesia, cuya renta de cada una está regulada en 2790 pesos al año, vacantes por fallecimiento de Dn. Francisco Xavier Ruiz de Eguino, de Dn. Juan de Dios Pey y Andrade, tesorero y electo chantre y de Dn. Miguel Vélez Ladrón de Guevara, y de los pretendientes que han ocurrido a solicitarlas. Sin fecha, 1797 (AGI, Santa Fe 727); consulta de 19 de julio de 1799 (AGI, Caracas 10); presentación de Dn. Juan Antonio Troconis a una ración de la iglesia catedral de Mérida de Maracaibo, de San Ildefonso 24 de agosto de 1799 (AGI, Caracas 952). 
Era oriundo de la provincia de Sevilla, en cuya capital se ordenó franciscano. Gran parte de su vida transcurrió en México, donde estuvo destinado en las misiones que los frailes tenían en el norte del virreinato novohispano. De su labor al frente del obispado de Mérida de Maracaibo se ha escrito mucho aunque creemos que no todo. Se han resaltado, a nuestro parecer, determinadas facetas sin duda de importancia de su quehacer como prelado entre 1784 y 1790 , mientras se han obviado los problemas que lo rodearon aquellos pocos años. Como se ha subrayado en páginas anteriores, la provincia de Mérida de Maracaibo tenía una serie de peculiaridades que la hicieron especialmente difícil no sólo para gobernadores sino también para virreyes y capitanes generales. En este contexto no es de extrañar que Ramos de Lora tuviera que sortear obstáculos poco comunes, con más o menos diplomacia y también con resultado variable. En este sentido, está documentado el titánico esfuerzo de Lora dirigido a echar a andar la diócesis, lo que le llevó en no pocas ocasiones a desencuentros con las autoridades civiles en su propósito de dejar perfectamente definido el ámbito de influencia del nuevo obispado. No hace mucho tuvimos la ocasión de publicar una investigación que abordaba precisamente estas cuestiones ${ }^{16}$

Dejemos a un lado al obispo y abordemos el papel que jugaron otros protagonistas. Habría que hablar de Carmen Delgado, una niña de apenas diez años, pero que fue juzgada con severidad por el párroco de la iglesia más antigua de Maracaibo, lo que daría lugar a un cruce de duras acusaciones entre este sacerdote y su padre Rafael Delgado, a la sazón, castellano de la Barra de Maracaibo. Se trata de un personaje, Rafael Delgado, bien documentado en los archivos; pasaba de los 40 años cuando tuvo lugar su enfrentamiento con el cura Troconis. Había nacido en la península Ibérica, en Navalcarnero, que por aquel entonces pertenecía a la provincia de Segovia ${ }^{17}$. Era hijodalgo y pertenecía a una influyente familia, como lo atestigua el hecho de que, años después, un hijo suyo

\footnotetext{
${ }^{16}$ María Dolores FuENTES BAJO (2005): «La justicia de un obispo. Los difíciles comienzos de la diócesis de Mérida-Maracaibo, 1784-1790». Fue presentado al XIII Congreso Internacional de AHILA que tuvo lugar en 2002 en la Universidade do Açores. Con posterioridad, se ha publicado en Procesos Históricos. Mérida (Venezuela) nº 7, 19 páginas.

${ }^{17}$ Era hijo de Manuel Delgado y María Ignacia Cardeña. Nació un 6 de febrero de 1746 y fue bautizado en la parroquia de la Asunción de Navalcarnero, once días después (Archivo de la Parroquia de la Asunción de Navalcarnero, Libro de Bautismos 12). En el catastro de la villa de Navalcarnero de 1753, aparece un cosechero de estado hijodalgo de nombre Manuel Delgado, presumiblemente su padre, habitando la casa 5 de la calle Cruz Verde. Tenía entonces 42 años de edad y tres hijos menores a su cargo. Dicho documento se custodia en el Archivo Municipal de Navalcarnero.
} 
regresara a tierras castellanas para hacerse cargo del mayorazgo de los Delgado en Navalcarnero ${ }^{18}$.

Rafael Delgado tuvo una larga y brillante carrera militar. Con anterioridad a su partida a América, tuvo diferentes destinos, el primero de ellos en la guarnición de la plaza de Ceuta. Corría el año de 1761 y Rafael era un cadete de apenas 15 años. Nos parece de mayor interés, sin embargo, analizar su trayectoria posterior; está documentada, en este sentido, su vinculación durante bastantes años al regimiento fijo de infantería de Cartagena de Indias ${ }^{19}$. Tiempo después, se registra la presencia de Rafael Delgado en Caracas, donde supo ganarse la confianza de los gobernadores. Se vincularía allí de forma especial con otro militar oriundo como él de la península, Joaquín Moreno de Mendoza, con cuya hija Francisca terminaría casándose en $1779^{20}$. En ese mismo año de 1779 tomó posesión del cargo de gobernador militar interino en la isla de Trinidad, puesto que desempeñaría poco tiempo, en parte debido a sus diferencias con otros representantes de la Corona ${ }^{21}$.

${ }^{18}$ Rafael Delgado y Moreno, el mayor de los hijos varones, vino a España en 1803 con este fin. Véase la instancia de Rafael Delgado y Moreno, teniente coronel de infantería retirado en Navalcarnero y agregado interinamente al batallón mayor de la plaza de La Coruña. Sin fecha, probablemente de julio o agosto de 1824 (Archivo General de Simancas, AGS, Secretaría de Guerra 7327, expediente 81 )

${ }^{19}$ Certificación de D. Antonio de Arévalo, comandante general de la provincia del Hacha, de los méritos de Rafael Delgado, de Cartagena de Indias 8 de febrero de 1774 (AGI, Caracas 152); certificación del gobernador Francisco de Santa Cruz, Maracaibo, 15 de marzo de 1778 (AGI, Caracas 152)

${ }^{20}$ Una real orden comunicada a través del gobernador de Caracas le dio licencia para casarse. Tenía fecha de Aranjuez 26 de junio de 1778. El matrimonio se celebró en la iglesia parroquial de Nuestra Señora de Altagracia de Caracas el 15 de febrero de 1779. Francisca había nacido ya en Caracas y era hija de Joaquín Moreno de Mendoza y Francisca de Salas. Los dos documentos pertenecen a AGI, Caracas 99.

${ }^{21}$ Cartas 2, 3, y 8 de Rafael Delgado a José de Gálvez, de Trinidad de Barlovento 29 y 30 de diciembre de 1779 y 13 de abril de 1780, respectivamente; memorial de Delgado, de Trinidad 18 de agosto de 1780; índice de representaciones y oficios que se remiten al excelentísimo señor don José de Gálvez, Secretario del Despacho Universal de Indias por el gobernador militar de la isla de Trinidad de Barlovento, de Trinidad 22 de agosto de 1780. Estos documentos en AGI, Caracas 152. Rosario SeVILla Soler (1989) es autora de un trabajo bastante esclarecedor sobre Trinidad y su dura trayectoria colonial, por decirlo en pocas palabras. La isla estuvo siempre poco poblada (sólo destacaban dos núcleos urbanos, San José de Oruña y Puerto España), denominándose primero provincia de Trinidad de Guayana y, desde 1731, Trinidad de Barlovento (El poder en las colonias menores. El caso de Trinidad. Madrid, Consejo Superior de Investigaciones Científicas). 
Pocos años más tarde, hacia 1784, lo encontramos en su último destino: castellano de la fortaleza de San Carlos en la Barra de Maracaibo ${ }^{22}$.

Hasta aquí nuestras pesquisas sobre Rafael Delgado. Debemos dar por terminada la lista de personas que se vieron involucradas de diferente manera en los hechos que tuvieron lugar en la parroquia de Maracaibo con la finalidad de pasar ya a su estudio.

\section{UNA NAVIDAD CARGADA DE ACONTECIMIENTOS}

\section{Los edictos de Ramos de Lora}

Nuestro punto de partida obligatoriamente se sitúa en unos edictos debidos a la pluma de Juan Ramos de Lora. Tienen fecha de finales de 1789 y estuvieron motivados, al parecer, por determinadas circunstancias que venían produciéndose en Maracaibo entre la población femenina. Se habían percibido, en este sentido, significativos cambios en sus hábitos de vestir. Hasta ese momento, había prevalecido la costumbre de que las mujeres se valieran de un determinado atuendo para acudir a los servicios litúrgicos, con independencia de su calidad. Se vestían, para este fin, con prendas de tono oscuro, muy tupidas, por lo general confeccionadas de lana, raso o tafetán ${ }^{23}$. Básicamente se trataba de la basquiña, es decir, una falda larga, el corpiño y el mantón, todo ello de color negro. Los pies se calzaban con zapatos de idéntico color ${ }^{24}$. Sin embargo, al finalizar la centuria, se introdujeron algunos cambios, reflejo, tal vez, de los nuevos tiempos que

\footnotetext{
${ }^{22}$ La fortaleza fue construida entre 1679 y 1682, según planos diseñados por Francisco Ficardo. Miguel SemPere MARTínez (2000) Maracaibo, ciudad y arquitectura. Universidad del Zulia, Facultad de Arquitectura y Diseño: Ediciones Astro Data, pp. 61-68) y Graziano GASPARINI (1985) Las fortificaciones del periodo hispánico en Venezuela. Caracas, Gráficas Armitano C.A., pp. 173188) recopilan interesante información sobre sus características. Volviendo a nuestro personaje, Rafael Delgado, la documentación sobre estos años en la fortaleza de San Carlos es abundante. Véase copia de carta del capitán Rafael Delgado, electo castellano de las fuerzas de la Barra de Maracaibo, de 18 de mayo de 1784 (Ags, Secretaría de Guerra 7176, Expediente 42); representación de Delgado, de Castillo de San Carlos 5 de abril de 1788 (AgI, Caracas 113); carta de Delgado, de Maracaibo 6 de junio de 1788 (Ags, Secretaría de Guerra 7168, Expediente 13); carta del capitán general de Caracas, de Caracas 15 de marzo de 1794 (Ags, Secretaría de Guerra, 7180, Expediente 13)

${ }^{23}$ Elina Lovera ReYes (1995): «Las mujeres y la iglesia en los tiempos coloniales», en: La mujer en la historia de América. Bajo la dirección de Ana Lucina García MALDONADO. Coordinadora Internacional, Lupe RumAzo. Caracas: Asociación civil La mujer y el V Centenario de América y Venezuela, p. 232; Carlos F. DuARTE (1984): Historia del traje durante la época colonial venezolana. Caracas: Gráficas Armitano, pp. 82, 110-111 y 129; Ermila Troconis De VeracoecheA (1999): «La iglesia y la mujer en el siglo XVIII». Montalbán, Caracas, n 32, p.126.

${ }^{24}$ Carta de Rafael Delgado. Castillo de San Carlos 3 de agosto de 1790. AgI, Caracas 375.
} 
empezaban a vislumbrarse en la región ${ }^{25}$. Como se apuntó en otro lugar, la adscripción de Maracaibo al virreinato neogranadino y, más tarde, a la Capitanía General de Venezuela supondría, a pesar de todas sus dificultades y contradicciones, el fin del aislamiento para nuestra provincia, a muy diferentes niveles. En este contexto pensamos que reside la clave para interpretar las nuevas modas en el vestir que empezaron a verse en Maracaibo. Está documentada, incluso, la fecha aproximada en que tuvo lugar su introducción; según algunos testimonios, esto sucedería en la década de los 80 y fueron modas, básicamente, traídas de la capital, de Santiago de León de Caracas $^{26}$. Las damas de la élite marabina, entre las que se encontraban esposas de oficiales reales, fueron acérrimas defensoras de las nuevas telas y hechuras; habría que incluir entre ellas a Francisca Moreno Salas que, a pesar de su supuesto destierro en la Barra de Maracaibo, fue una de las primeras en valerse de los nuevos "paños" para ir a la iglesia ${ }^{27}$.

El traje, en cuestión, introducía ciertas novedades. Una era el color; frente a la sobriedad y el recato del manto negro, el de ahora era mucho más vistoso al valerse de tonalidades, por lo común, más claras. A partir de ese momento, las mujeres dejaron de estar uniformadas en los templos, diferenciándose, a primera vista, unas de otras. Mientras que el anterior era grueso y no se ajustaba al cuerpo, la hechura del nuevo era diferente pues marcaba brazos y talle, y, aunque más largo, el fino lino empleado en su confección le confería unas calidades transparentes e insinuantes. Juan Antonio Troconis, con ese dominio de la palabra que le caracterizaba, describía las nuevas mantillas como maléficas telas de araña, aludiendo a lo sutil de su textura, al tiempo que daba por supuesto los diabólicos fines que, sin duda, perseguirían sus usuarias al cubrirse con ellas.

${ }^{25}$ Sobre la ropa usada por las mujeres en el siglo XVIII véase: Rafaella SARTI (2002): Vida en familia. Casa, comida y vestido en la Europa moderna. Barcelona: Crítica, pp. 258-269; Elena MARTíNEZ AlCÁZAR (2007-2008): «Características del atuendo español del setecientos a través de la documentación notarial de Murcia». Imafronte $\mathrm{n}^{\circ}$ 19-20, pp. 177-193; Mary MONEY (1983): Los obrajes, el traje y el comercio de ropa en la Audiencia de Charcas. La Paz, Instituto de Estudios Bolivianos, pp. 127-131. Para el caso concreto de Venezuela, puede consultarse Antonio GONZÁLEZ ANTíAs (1995): «La mujer en el ambiente social de la Venezuela colonial», en La mujer en la historia de América. Bajo la dirección de Ana Lucina García MALDONADO. Coordinadora Internacional, Lupe RumAzo. Caracas: Asociación civil La mujer y el V Centenario de América y Venezuela, pp. 109-112; Rosa María Guillén SERRANo (1995): «Vida cotidiana en Cumaná en vísperas de la independencia», en: Mena GarcíA, Carmen; Eugenio Martínez, Ángeles; SARABIA VIEJO, Justina: Venezuela en el Siglo de las Luces. Sevilla-Bogotá: Muñoz Moya y Montraveta editores, pp. 201-218.

${ }^{26}$ Carta de Juan Antonio Troconis, de Maracaibo 27 de julio de 1790. AgI, Caracas 375.

27 Declaración de Dn. José Francisco del Pulgar, cura capellán castrense, de Maracaibo 13 de julio de 1790. AGI, Caracas 375. 
"No podía señor faltar a estos paños y su indecente uso algún oropel de honestidad, teniendo tanto interés y estando tan empuntado en mendigarle vuestro castellano. Con efecto, se les aplica el de que su tamaño y el modo cuidadoso de ajustarse al cuerpo proporciona a las mujeres ir más cubiertas que iban antes y que es menester. Y como este brillo los hace sobresalir cuanto abulta exceder los conatos del apóstol (de quien hubieron las de aquel sexo el precepto de cubrir en el templo solamente las cabezas) nada obsta que sea brillo de oro falso. Tenga el velo apariencia de cubrir de talle a cabeza las mujeres y no importa que lo haga remedando a las telarañas, así es telas arañas las que afanando también como el cubrir la pared donde se extienden, no sirven sino de artificiosa emboscada a sus artistas y de peligrosa red a las incautas moscas. No importa, vuelvo a decir, pues con tal salvaguardia y bajo el auspicio de un virtuoso honor se espera que correrá en triunfo erguido el cuello esa estudiada cobertera del desorden, esa dolosa hidra, ese trampantojo: que las vistas inexpertas en discernir lo honesto de su contrario, confundirán esto con aquello, como sucede con los vidros (sic) resplandecientes a los que no tienen inteligencia de piedras preciosas..."28

El edicto primero del obispo Lora se hizo eco, en seguida, de las inquietudes expresadas, entre otros, por el párroco Troconis; no obstante, precisó de un segundo edicto, porque la respuesta de los eclesiásticos del lugar no fue unánime, por lo visto. Gracias a las declaraciones de diferentes testigos, podemos saber su contenido con cierta fiabilidad. El franciscano Ramos de Lora censuraba con severidad la mudanza en el vestido y amenazaba con las más duras reconvenciones a las transgresoras; instaba, de forma contundente también, a los eclesiásticos de Maracaibo a no admitir en sus templos a las mujeres que se empeñaran en acudir con la citada indumentaria; debían, sin más, hacerlas salir de la casa de Dios, teniendo potestad para acudir a censuras aún más severas ${ }^{29}$.

${ }^{28}$ Carta de Juan Antonio Troconis, de Maracaibo 27 de julio de 1790. AgI, Caracas 375.

${ }^{29}$ La Iglesia venezolana siempre estuvo preocupada por reglamentar la vida de las mujeres. Los edictos de Lora no fueron un caso aislado; en este sentido se manifestaron igualmente los prelados Diego Antonio Diez Madroñero, Mariano Martí, Francisco de Ibarra o Santiago Hernández Milanés, los dos últimos al alborear ya el siglo XIX. Véase, Marina Helena HernándeZ ARMAS (1998): "Artificiosas hermosuras. Indumentaria, adornos y encantos picarescos en Venezuela del siglo XVIII». Tierra Firme, Caracas no 62, pp. 267-277; José Ángel RodRíGUEZ (2006): «Féminas en la mira. Percepciones sagradas y profanas de la mujer venezolana en el siglo XIX», en: O'PHELAN GODOY, Scarlett; ZEGARRA FloREZ, Margarita (editoras): Mujeres, familia y sociedad en la historia de América Latina. Siglos XVIII-XXI. Lima: Cendoc- Mujer, Pontificia Universidad Católica del Perú, Instituto Riva Agüero, Instituto Francés de Estudios Andinos, pp. 367-371; José Pascual MorA GARCíA (2004): «La mujer tachirense de los Andes venezolanos, siglo XIX». Fermentum, Mérida (Venezuela), Año 14 n 41 , p. 581. 


\section{La Misa del Gallo de 1789}

Está documentado, en otro orden de ideas, que tuvieron conocimiento de estos edictos los fieles de Maracaibo, en concreto del segundo de ellos, en la Misa de Nochebuena $^{30}$. Disponemos de información acerca de la acogida de estos mensajes del obispo; al menos en determinados círculos, consta que no fueron atendidos: las mujeres siguieron luciendo las nuevas modas en las iglesias, a pesar del celo de curas y frailes por obedecer al diocesano. Determinados testigos presentados por el cura Troconis mencionaban, en este sentido, la tozudez de algunas señoras -entre las que citaban, por supuesto, a la esposa del castellano- por lucir las prendas prohibidas $^{31}$. La respuesta de los eclesiásticos de Maracaibo no se haría esperar y fueron varios los casos de mujeres desalojadas de los templos, sin reparar en su edad o condición. Las más de las veces, la censura obedecía a las finas y vistosas mantillas que llevaban, si bien está registrado que en ocasiones fue el tipo de zapatos -que no se correspondía con el que con el que tradicionalmente estaba al uso- lo que originó el conflicto ${ }^{32}$.

\section{Una niña de nombre Carmen Delgado}

Otros pormenores de aquella Navidad son de interés. Nos detendremos ahora en el día 2 de enero de 1790. Todo comenzó en la misa de la parroquia de las seis de la mañana. A pesar de lo temprano de la hora, era la misa más solemne de las celebradas; en eso también parecía guiarse Maracaibo por los usos y costumbres de la feligresía de Caracas. El caso es que a aquella hora acudió Carmen, la hija primogénita del castellano Rafael Delgado, en compañía solo de dos criadas ya que su madre guardaba reposo en la casa que la familia tenía en la ciudad, tras haber dado a luz unos días antes ${ }^{33}$.

Disponemos de diferentes descripciones de Carmen Delgado, aunque están lejos de coincidir. Para su padre no era más que una párvula de 10 años escasos; sin

${ }^{30}$ Se hizo público en la parroquia, en la iglesia de San Francisco y en la viceparroquia de San Juan de Dios, como se dice de forma expresa en la carta de Juan Antonio Troconis al gobernador Joaquín Primo de Rivera, de Maracaibo 10 de mayo de 1790. AgI, Caracas 375.

${ }^{31}$ Declaración del presbítero Dn. José Francisco del Pulgar, de 13 de julio de 1790. AGI, Caracas 375.

${ }^{32}$ En una certificación rubricada por el gobernador Joaquín Primo de Rivera (de Maracaibo 15 de mayo de 1790. AGI, Caracas 375) se dice que algunas criadas suyas fueron reprendidas en la iglesia, unas veces porque eran blancos sus zapatos y, otras, porque los llevaban sin hebillas.

33 Doña Francisca había llegado a Maracaibo en los primeros días de diciembre y su hijo nació el día 11 de ese mes, como informaba el castellano en su carta de 3 de agosto de 1790. AGI, Caracas 375. 
embargo, para los testigos del cura Troconis estaba muy crecida y con formas femeninas definidas, razón por la que, a cierta distancia, se podía confundir con una mujer no demasiado alta, de las muchas que había en la ciudad ${ }^{34}$. En estas diferentes apreciaciones puede verse una intencionalidad clara; el castellano se empeñaba en recalcar los pocos años de su hija, para subrayar el sinsentido de la reacción del párroco. La información que adjuntaba Juan Antonio Troconis sostenía lo contrario; reiteraba sus hechuras de mujer para justificar, de este modo, la censura del eclesiástico. Volviendo a Carmen, nuestros informantes diferían también en cuanto a su vestimenta de aquel día. Si atendemos a las alegaciones de su padre, las ropas que lucía en la iglesia no eran de las censuradas. Si bien el color de la mantilla con que se cubría no era negro sino blanco, la tela era muy tupida y el resto de su traje tenía un tono oscuro. Era cierto que su familia mantenía estrechos vínculos con Caracas y que de allí había llegado, entre otras prendas, la que vestía en el templo; pero en su casa, insistía el castellano, se velaba por vestir en todo momento con honestidad y recogimiento, máxime cuando se trataba de acudir a la iglesia. Sin embargo, otros documentos facilitaban una versión distinta del aspecto de la muchacha. De esta forma, dejaban bastante claro no solo que su mantón era de los prohibidos sino que, a sabiendas, lo llevó aquel domingo. Añadían, por si esto fuera poco, que a ello la había empujado su misma madre diciéndole que, de no estar guardando cama, ella misma se lo hubiera puesto ${ }^{35}$.

\section{El dos de enero y la primera misa del día}

Dejemos a un lado las disquisiciones sobre el aspecto de la hija, supuestamente gordita, del castellano de la Barra de Maracaibo y pasemos a narrar lo que a continuación pasó. Los hechos se desarrollaron con tal rapidez que sorprendieron a la misma feligresía. Al poco de salir de la sacristía el vicario Juan Antonio Troconis, no obstante el recogimiento con que caminaba preparándose para decir la misa, tuvo ocasión de levantar la vista y descubrir lo que juzgó una falta digna de las mayores censuras; a poca distancia de él, una feligresa vestía la mantilla censurada de forma expresa en el edicto hecho público pocos días antes, lo que hacía aún más grave la transgresión. En la documentación se recogen, incluso, las airadas palabras proferidas por Troconis, instando a Carmen Delgado, a la que

34 Las menores de 12 años se clasificaban de "párvulas"; a partir de esa edad se incluían en el grupo de "doncellas", que eran las jóvenes que ya estaban en edad de casarse. Véase Pilar GonZALBo AIZPURU (2002): «Niñas maduras y jóvenes viudas en el México colonial», en PÉREZ CANTÓ, Pilar; ORTEGA LóPEZ, Margarita, editoras: Las edades de las mujeres. Madrid: Universidad Autónoma, pp. 31-33.

35 Carta de Rafael Delgado. Castillo de San Carlos 3 de agosto de 1790; declaración de Dña. Melchora Suárez, de Maracaibo 7 de julio de 1790. Ambos documentos en AGI, Caracas 375. 
confundió con una mujer adulta, a abandonar ipso facto la iglesia, al tiempo que le advertía que debía darse por excomulgada. En este sentido, era bastante explícita la declaración de una esclava morena de nombre María Sacramento:

“... Que le consta por haber ido la declarante con la referida hija del señor castellano, que ésta se presentó con el paño prohibido que fue el motivo porque el señor que la presenta la mandó salir con las palabras siguientes: que aquella mujer del paño se saliese porque sino no decía la misa y que las mujeres del paño se habían de ver excomulgadas por querer ir así y que por esta razón como la de haber sido a un mismo tiempo divisarla y mandarla salir y ser la niña de una estatura que al verla no parece sino mujer, hace juicio no pudo conocerla y también por lo que lleva dicho antes de no poner reparo en clases de sea quien fuere..." 36

Algunos testigos hacían recaer toda la responsabilidad de lo sucedido en la propia Carmen que, conocedora de las severas recomendaciones de Juan Ramos de Lora, desoyó las advertencias que le hicieron al respecto. De esta forma, impuso primero su deseo de asistir de esa guisa a la parroquia y no a otros templos que incluso estaban más cercanos a la casona familiar y donde, con toda probabilidad, su atuendo habría pasado más desapercibido, al no revestir tanto ceremonial la celebración de la misa. Una vez en la parroquia, la niña-mujer insistió en ocupar uno de los lugares más visibles, a pesar de los consejos recibidos de las damas que se encontraban próximas y que le recordaron, en vano, el mensaje del diocesano ${ }^{37}$. Las enérgicas palabras de Juan Antonio Troconis, puntualizaban por otro lado estas fuentes, nunca persiguieron ser una afrenta contra Rafael Delgado y su familia, dado que el sacerdote reparó sólo en el "paño" prohibido y de ningún modo en la persona que lo vestía, dada la rapidez con que todo se produjo. De sobra era conocido, además, que no era la primera vez que obraba así.

Todos y cada uno de estos alegatos serían sopesados y, en la medida de lo posible, rebatidos por el castellano de la barra de Maracaibo. Utilizaría para ello argumentaciones de muy variado signo, no exentas de contradicciones en determinados momentos. Insistió, así, repetidas veces, en que no le asistía la razón al vicario en lo relativo a las ropas de la niña; si bien era cierto que seguían las modas de Santiago de León de Caracas, no eran de las recriminadas por el prelado, debido a su preocupación porque los vestidos de su familia se caracterizaran por su modestia. No obstante, en otros párrafos defendía que la ropa era un elemento de distinción de las personas y, como tal, la que lucían su mujer e hijos estaba acorde

\footnotetext{
${ }^{36}$ Declaración de María Sacramento de 10 de julio de 1790. AgI, Caracas 375.

${ }^{37}$ Declaración de María Sacramento.
} 
con su posición acomodada en la sociedad. Rafael Delgado llegaba a alegar que, aún en el supuesto de que le hubiera asistido la razón al vicario y que el atuendo de la niña distara de ser el permitido, en la fecha en que tuvieron lugar los desagradables sucesos, el 2 de enero, no podían tener vigor todavía los edictos del obispo al no haber transcurrido el tiempo pertinente; desde su publicación en las iglesias, en efecto, habían pasado muy pocas fechas, máxime recordando que en la Navidad había varios días de asueto. Por otra parte, existían unas circunstancias especiales que justificaban en parte que la familia Delgado no hubiera sabido de los edictos; como de todos era conocido, el militar estaba destinado en la Barra de Maracaibo, lugar a donde no había llegado noticia alguna de ellos. En cuanto a su esposa, si bien se había trasladado a la ciudad, a causa de su delicado estado de salud, en modo alguno estuvo en disposición de atender a novedades y, menos aún, de poder advertir en este sentido a su hija mayor. Rafael Delgado, por último, consideraba que los hechos ocurridos revestían una especial gravedad. Hacía mención del desastroso efecto que las palabras del sacerdote tuvieron en la muchacha que, por las circunstancias antes citadas, prácticamente se encontraba sola en la iglesia y en una situación de total desvalimiento. Concluía subrayando que consideraba una ofensa a su honor todo lo acontecido.

“... La inocente criatura con tan bochornoso vejamen, salió llorosa para su casa: y la madre recibió herida tan sensible en su crítica situación de enfermedad, con la ternura de ver castigada sin culpa y afrentosamente su hija. Afligiéndola como corresponde el que recayendo la pena trascendentalmente hacia mí y ella con toda la familia me hallaba ausente. Y que el arrojar de la iglesia con voz de excomulgada a su hija fue con escándalo de toda clase de gente que glosaran el paraje y sus circunstancias con ideas bochornosas para cuantos lo oigan en agravio del moral y obediencia que guardamos a las debidas providencias de los prelados eclesiásticos..." 38

\section{Las autoridades se hacen eco}

Según consta en el voluminoso expediente, las reclamaciones de Rafael Delgado por lo sucedido fueron vistas en diferentes instancias. Al menos en dos ocasiones se dirigió al propio autor de los edictos, al obispo Juan Ramos de Lora, en protesta por las extralimitaciones de su vicario; tras examinar con detenimiento las aseveraciones contenidas en sus escritos, reconoció el prelado en Juan Antonio Troconis un exceso de celo en llevarlos a efecto, pues las circunstancias de la niña en cuestión y de su indumentaria eran otras bien distintas. No obstante, Juan

${ }^{38}$ Carta de Rafael Delgado, de Castillo de San Carlos 3 de agosto de 1790. AGI, Caracas 375. 
Ramos recomendaba al castellano no seguir adelante en su pleito con Troconis, actitud conciliadora que bien podía obedecer a la grave enfermedad que padecía ya Ramos de Lora y que le llevaría a un fatal desenlace al finalizar ese mismo año de 1790. Pero bien pudiera ser también que la respuesta de Ramos de Lora estuviera relacionada con cierta intención de alejar a su protegido y fiel aliado en su campaña contra el vestido femenino de pleitos interminables con los oficiales del rey ${ }^{39}$.

Sabemos que el castellano de la Barra desoyó las recomendaciones de Lora y que a sus peticiones dieron curso las autoridades locales. Se fechan un año después, en 1791, diferentes resúmenes del Consejo de Indias extractando los muchos documentos adjuntados por Rafael Delgado, así como un real despacho cuyo destinatario ya era el nuevo obispo electo para la diócesis de Mérida-Maracaibo, Manuel Cándido Torrijos. En este nuevo documento eran atendidas las quejas de Rafael Delgado y se instaba a Torrijos, una vez llegado a Venezuela, a encargarse personalmente de que Juan Antonio Troconis diera de forma pública una satisfacción, al tiempo que incluía severas advertencias relativas a la prudencia que debía guiar sus providencias en lo sucesivo ${ }^{40}$.

\section{ALGUNAS REFLEXIONES}

Ciertamente fue la de 1789 una Navidad llena de acontecimientos reveladores. El estudio de los problemas derivados de la aplicación de los edictos de Juan Ramos de Lora puede servirnos para hacer valoraciones de carácter más general. La primera, podría ser, acerca de la gobernación de Maracaibo. La pequeña o gran historia que se ha rescatado de los archivos es así y no de otro modo por las características tan especiales de Maracaibo, una provincia que empezaba a salir de un aislamiento secular en el periodo que se estudia, aunque para ello debía hacer frente a importantes contradicciones internas. En relación a los protagonistas de los hechos que se han narrado, lo primero que salta a la vista es que son personajes de una extraordinaria fortaleza, los más adecuados quizá a un medio tan difícil como es la gobernación que se estudia. Rafael Delgado encarna así al prototipo de militar español en quien puso sus miras la Corona para desempeñar cargos de responsabilidad en estas zonas de colonización tardía.

Sobre la pequeña tragedia que se escenificó en la parroquia de Maracaibo podrían hacerse algunas consideraciones. Las fricciones entre los eclesiásticos y los oficiales reales fueron bastante frecuentes en la colonia. En este sentido, puede considerarse un episodio más el enfrentamiento verbal y epistolar entre el cura

\footnotetext{
${ }^{39}$ Carta de Rafael Delgado.

${ }^{40}$ Real despacho al obispo electo, de Palacio 24 de agosto de 1791. AgI, Caracas 375.
} 
Troconis y el castellano de la Barra. En el Archivo General de Indias de Sevilla hemos tenido oportunidad de consultar otros expedientes similares. Obligada es una última reflexión sobre el vestido femenino; a lo largo de nuestro trabajo se han recogido apuntes relativos a la transformación que experimenta a finales del setecientos, en clara relación pensamos, con las nuevas perspectivas que se perfilan para la región tras las remodelaciones político-administrativas de los Borbones.

\section{BIBLIOGRAFÍA}

DuARTE, Carlos F.: Historia del traje durante la época colonial venezolana. Caracas: Gráficas Armitano, 1984.

FERNÁNDEZ HERES, Rafael: «Factores históricos determinantes para la creación del arzobispado de Caracas (Homenaje con motivo de su bicentenario, 1803-2003)». Boletín de la Academia Nacional de la Historia, Caracas n ${ }^{\circ} 346$, abril-junio 2004, pp. 169-210.

FUENTES BAJO, María Dolores: «La justicia de un obispo. Los difíciles comienzos de la diócesis de Mérida-Maracaibo, 1784-1790». Procesos Históricos. Mérida (Venezuela) nº 7 , enero 2005, 19 páginas.

FUENTES BAJO, María Dolores: «Estudio de una provincia: Maracaibo, siglo XVIII». Revista Trocadero Cádiz no 17, 2005, pp. 249-265.

FuENTES BAJO, María Dolores: "Gobernar en una provincia de frontera: Maracaibo 1750-1775». Revista Historia, Métodos y Enfoques. San Juan (Argentina) nº 1, 2008, pp. 928.

García Gallo, Alfonso: «La Capitanía General como institución de gobierno político en España e Indias en el siglo XVIII». Memoria del III Congreso Venezolano de Historia. Tomo I. Caracas: Academia Nacional de la Historia, 1979, pp. 535-582.

GASPARINI, Graziano: Las fortificaciones del periodo hispánico en Venezuela. Caracas, Gráficas Armitano C.A., 1985.

Gómez PARENTE, Odilo: Fray Juan Ramos de Lora, obispo insigne y sembrador de cultura. : Documentos inéditos sobre su vida y actividad al frente de la diócesis de Mérida de Maracaibo. En el 250 aniversario de su natalicio Los Palacios-Sevilla (1722-1972). Caracas: Edición del Ejecutivo del Estado Mérida, 1972.

GÓMEZ PARENTE, Odilo: Ilustrísimo padre fray Juan Ramos de Lora, fundador de la Universidad de los Andes. Caracas: Universidad Católica "Andrés Bello" Instituto de Investigaciones Históricas 1974.

GonZALbo AizPurU, Pilar: «Niñas maduras y jóvenes viudas en el México colonial», en: Pérez CANTÓ, Pilar; ORTEGa LóPEZ, Margarita (editoras): Las edades de las mujeres. Madrid, Universidad Autónoma, 2002, pp. 21-39

González Antías, Antonio: «La mujer en el ambiente social de la Venezuela colonial», en: La mujer en la historia de América. Bajo la dirección de Ana Lucina García Maldonado. Coordinadora internacional, Lupe Rumazo. Caracas: Asociación civil La mujer y el V centenario de América y Venezuela, 1995, 93-142.

Guillén Serrano, Rosa $\mathrm{M}^{\mathrm{a}}$ : «Vida cotidiana en Cumaná en vísperas de la independencia», en: Mena García, Carmen; Eugenio MarTíneZ, Ángeles, SARABIA 
VIEJO, Justina: Venezuela en el Siglo de las Luces. Sevilla-Bogotá: Muñoz Moya y Montraveta editores, 1995, pp. 201-230.

HERNÁNDEZ ARMAS, Marina Helena: «Artificiosas hermosuras. Indumentaria, adornos y encantos picarescos en Venezuela del siglo XVIII». Tierra Firme, Caracas nº 62, 1998, pp. 267-277.

LOVERA REYES, Elina: «Las mujeres y la iglesia en los tiempos coloniales», en: $L a$ mujer en la historia de América. Bajo la dirección de Ana Lucina GARCÍA MALDONADO. Coordinadora Internacional, Lupe RuMAZO. Caracas: Asociación civil La mujer y el V centenario de América y Venezuela, 1995, pp. 221-255.

Maldonado Viloria, Zulimar: «José Domingo Rus: un diputado maracaibero en las Cortes de Cádiz durante la independencia venezolana», en: Poder y mentalidades en España e Iberoamérica (siglos XVI-XX): implicaciones y actores: II Seminario Hispano Venezolano, Maracaibo 2001, pp. 187-207.

MAquedA ABREU, Consuelo: «Diplomacia, reformismo y virreinato de Nueva Granada en los inicios del siglo XVIII». Anuario de Historia de Derecho Español, n ${ }^{\circ} 74$, enero 2004, pp. 229-290.

MARTíNEZ AlCÁZAR, Elena: «Características del atuendo español del setecientos a través de la documentación notarial de Murcia». Imafronte n 19-20, 2007-2008, pp. 177193.

MONEY, Mary: Los obrajes, el traje y el comercio de ropa en la Audiencia de Charcas. La Paz: Instituto de Estudios Bolivianos 1983.

MORA GARCÍA, José Pascual: «La mujer tachirense de los Andes venezolanos, siglo XIX». Fermentum, Mérida (Venezuela), Año 14 n 41 , septiembre-diciembre 2004, pp. 580-594.

Morón, Guillermo: «La Real Audiencia de Caracas: unidad política de Venezuela». Boletín de la Academia Nacional de la Historia, Caracas nº 275, julio-septiembre 1986, pp. 579-590.

NÓBREGA, Enrique: «Notas sobre la élite militar en la provincia de Maracaibo: 17501814», en: MENA GARCÍA, Carmen; Eugenio Martínez, Ángeles y SARABIA Viejo, Justina: Venezuela en el Siglo de las Luces. Sevilla-Bogotá: Muñoz Moya y Montraveta editores, 1995, pp. 255-281.

NUNES DÍAS, Manuel: «Venezuela en las reformas estructurales del sistema colonial español». Memoria del I Congreso Venezolano de Historia. Tomo II. Caracas: Academia Nacional de la Historia, 1972, pp. 117-162.

Porras CARDOzo, Baltasar E.: El ciclo vital de fray Juan Ramos de Lora. Mérida: Ediciones del Rectorado-Universidad de los Andes, 1992.

RoDRíGuEZ, José Ángel: «Féminas en la mira. Percepciones sagradas y profanas de la mujer venezolana en el siglo XIX», en: O’PHELAN GODOY, Scarlett; ZEGARRA FloreZ, Margarita (editoras): Mujeres, familia y sociedad en la historia de América Latina. Siglos XVIII-XXI. Lima: CENDOC- Mujer, Pontificia Universidad Católica del Perú, Instituto Riva Agüero, Instituto Francés de Estudios Andinos, 2006, pp. 367-387.

SARTI, Rafaella: Vida en familia. Casa, comida y vestido en la Europa moderna. Barcelona: Crítica, 2002. 
SEMPERE MARTíneZ, Miguel: Maracaibo, ciudad y arquitectura. Universidad del Zulia, Facultad de Arquitectura y Diseño: Ediciones Astro Data, 2000, pp. 37-38

SEVIlla Soler, Rosario: El poder en las colonias menores. El caso de Trinidad. Madrid, Consejo Superior de Investigaciones Científicas, 1989).

TROCONIS DE VERACOECHEA, Ermila: «La iglesia y la mujer en el siglo XVIII». Montalbán, Caracas nº 32, 1999, pp. 121-132.

VÁSQUEZ DE FERRER, Belín: «Maracaibo y su espacio histórico (Siglo XVIII)». Tierra Firme, Caracas no 10, 1985, pp. 215-236.

1 - Provincia de Maracaibo, escenario de nuestra pequeña historia. 
2 - Foto antigua de la iglesia matriz de Maracaibo. En su interior se celebró una misa el día 2 de enero de 1790 que analizamos en estas páginas.

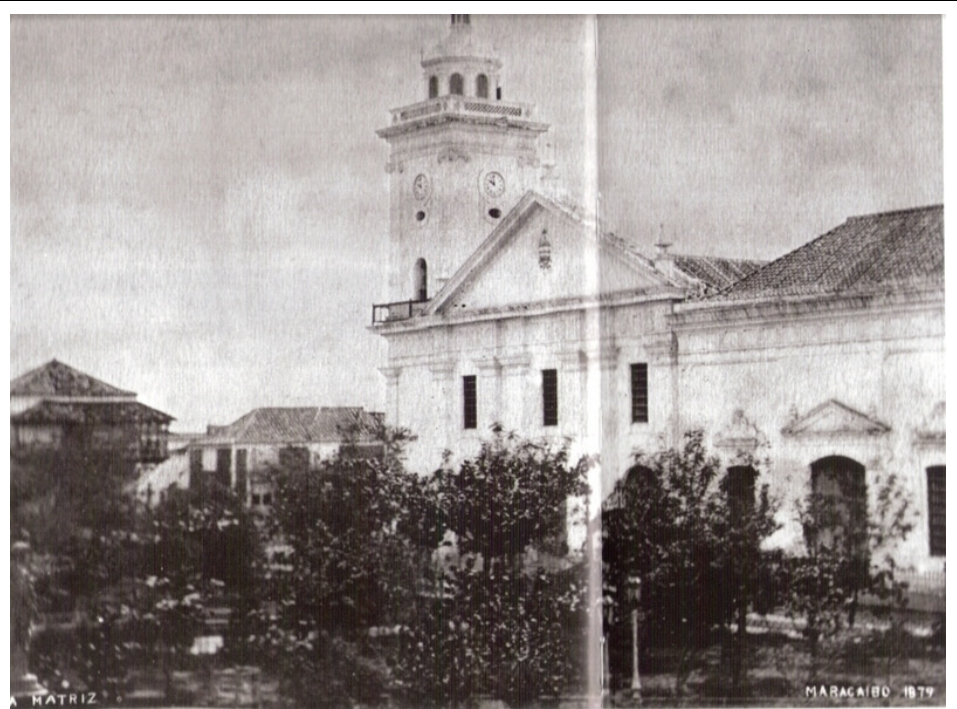

3 - Rafael Delgado fue castellano de la Barra de Maracaibo desde 1784. En la imagen, el castillo de San Carlos de la Barra.

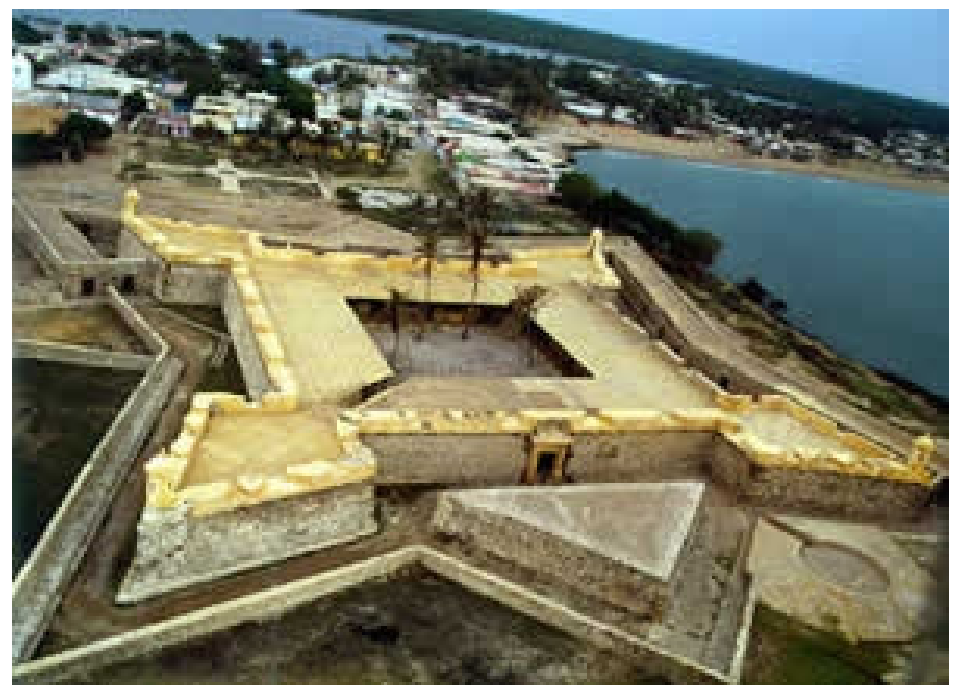

